\title{
Evaluation Indexes and Spatial-Temporal Features towards Urban Resilience of Sichuan Province in China from 2003 to 2013
}

\author{
Bo Pu ${ }^{1,2 *}$, Yanjun Qiu ${ }^{3}$, Zhiwei Tang² \\ ${ }^{1}$ School of Business and Tourism, Sichuan Agricultural University, Chengdu, China \\ ${ }^{2}$ School of Public Affairs and Administration, University of Electronic Science and Technology of China, Chengdu, China \\ ${ }^{3}$ School of Civil Engineering, Southwest Jiaotong University, Chengdu, China \\ Email: *ppuubo@hotmail.com
}

How to cite this paper: Pu, B., Qiu, Y. J., \& Tang, Z. W. (2022). Evaluation Indexes and Spatial-Temporal Features towards Urban Resilience of Sichuan Province in China from 2003 to 2013. Current Urban Studies, $10,14-24$

https://doi.org/10.4236/cus.2022.101002

Received: December 31, 2021

Accepted: January 25, 2022

Published: January 28, 2022

Copyright $\odot 2022$ by author(s) and Scientific Research Publishing Inc. This work is licensed under the Creative Commons Attribution International License (CC BY 4.0).

http://creativecommons.org/licenses/by/4.0/

(c) (i) Open Access

\begin{abstract}
New pattern urbanization, which is explored and developed in China for improving urban resilience and reducing urban vulnerability. Urban resilience is a comprehensive ability of a city for dealing with the uncertainty risk disasters through a combination of urban economy, urban engineering, urban society and urban ecology. When the city system and its subsystems have certain resilience in development, it will promote sustainable development. How to assess urban resilience? What is the spatial-temporal law on the development of urban resilience? These answers have an important practical significance for promoting the construction of the modern urbanization and sustainable development of cities and regions. Based on the above, this study constructed the measurement system on urban resilience, chose 21 cities of Sichuan province in China as a case, and analyzed the spatial-temporal law on the development of urban resilience empirically. The conclusions are as follows: The level of urban resilience was on the rise, and the characteristics of spatial heterogeneity on urban resilience were presented, and the spatial agglomeration degree increased gradually. The resilience of urban economic system, urban engineering system, and urban ecological system revealed a cluster characteristic in Sichuan province, but urban social system was not obvious.
\end{abstract}

\section{Keywords}

Urban Resilience, Assessment System, Spatial-Temporal Evolution, Sustainable Development 


\section{Introduction}

In the process of social and economic development, city faces the pressure of population concentration, resource consumption and environmental pollution. Uncertainty events brought by natural hazard and human-made disasters more frequent in urban area, with growing impact on city's economic and social development. Urban diseases become apparent indefinitely, which will increase the potential social and economic losses in the city. Urban resilience is the ability of an urban system, urban community, or urban society exposed to hazards to resist, absorb, accommodate, and recover from the effects of a hazard promptly and efficiently (Jha, Miner, \& Stanton-Geddes, 2013). Urban resilience includes four components, that are infrastructural, institutional, economical, and social. The practice of urban construction in advanced countries shows that resilient city construction is a more effective way to do with potential threats, such as flood, drought, terrorist activity and air pollution (Jha, Miner, \& Stanton-Geddes, 2013). Theoretically, the resilient city is a city that has the capacity to undertake, recover and prevent various potential impacts or shocks on urban engineering, economic, social and environmental. Resilient city has been a hotspot in the development of urban areas now (Pu \& Qiu, 2016).

China is facing the pressure of urbanization, and how to improve urban resilience and urban sustainable development, to improve socio-economic progress (Pu \& Qiu, 2015; Suárez et al., 2016). Sichuan is an important economic center in Western China, its engineering, social, economic and environmental development level directly determines the level of urbanization construction of Sichuan, is a matter of Sichuan's dream of building a powerful agricultural province. How to measure urban resilience? What is the spatial-temporal law on the development of urban resilience? Especially the earthquake in 2008, whether did it impact of urban resilience of Sichuan province, it is just an interesting question.

Researchers from multiple disciplines are studying the feedback, dynamics, and behavior of urban vulnerability and urban resilience in the face of urban crisis, such as the axioms and mean of urban resilience (Campanella, 2006; Surjan, Sharma, \& Shaw, 2011; Wilkinson, 2012), Climate change and urban resilience (Childers et al., 2012; Grimm et al., 2008; Leichenko, 2011), spatial planning and urban resilience in the flood risk (Tyler \& Moench, 2012; Deppisch \& Schaerffer, 2011; Cruz et al., 2013), urban resilience and human-dominated ecosystems (Lu, 2014), urban infrastructure systems (Ernstson et al., 2010; Wilbanks et al., 2012), urban resilience index (Ouyang \& Wang, 2015; Attoh-Okine, Cooper, \& Mensah, 2009), urban social resilience (Sellberg, Wilkinson, \& Peterson, 2015) and resilient cities (Cutter, Burton, \& Emrich, 2010; Desouza \& Flanery, 2013; Vale, 2014). Furthermore, topics on urban resilience and its related domain have become hot-debated focus (Pu \& Qiu, 2016; Beilin \& Wilkinson, 2015). It is necessary to describe the status qua on urban resilience measure for exploring urban and regional development.

In this article, we will establish an evaluation system of urban resilience; iden- 
tify the spatial-temporal features of urban resilience of Sichuan province.

\section{Materials and Methods}

About research route, firstly, form four subsystems of urban resilience; secondly, collect and deal with the data; thirdly, get urban subsystem index and a composite index; then, analyse the result on urban resilience; finally, feedback message. Detailed research route is illustrated in Figure 1.

\subsection{Index Choice}

Four subsystems of urban resilience which include urban engineering subsystem, urban economic subsystem, urban society subsystem, and urban ecology subsystem (see Table 1).

Two indicators of urban engineering subsystem have been selected, such as communication index and livelihood protection index. Some indicators of urban economic subsystem have been observed out, including economic potential index, economic effectiveness index, and economic innovation index. Society development index and human development index have been picked for urban society subsystem. Meanwhile, environmental efficiency index and environmental governance index have formed for urban ecology subsystem.

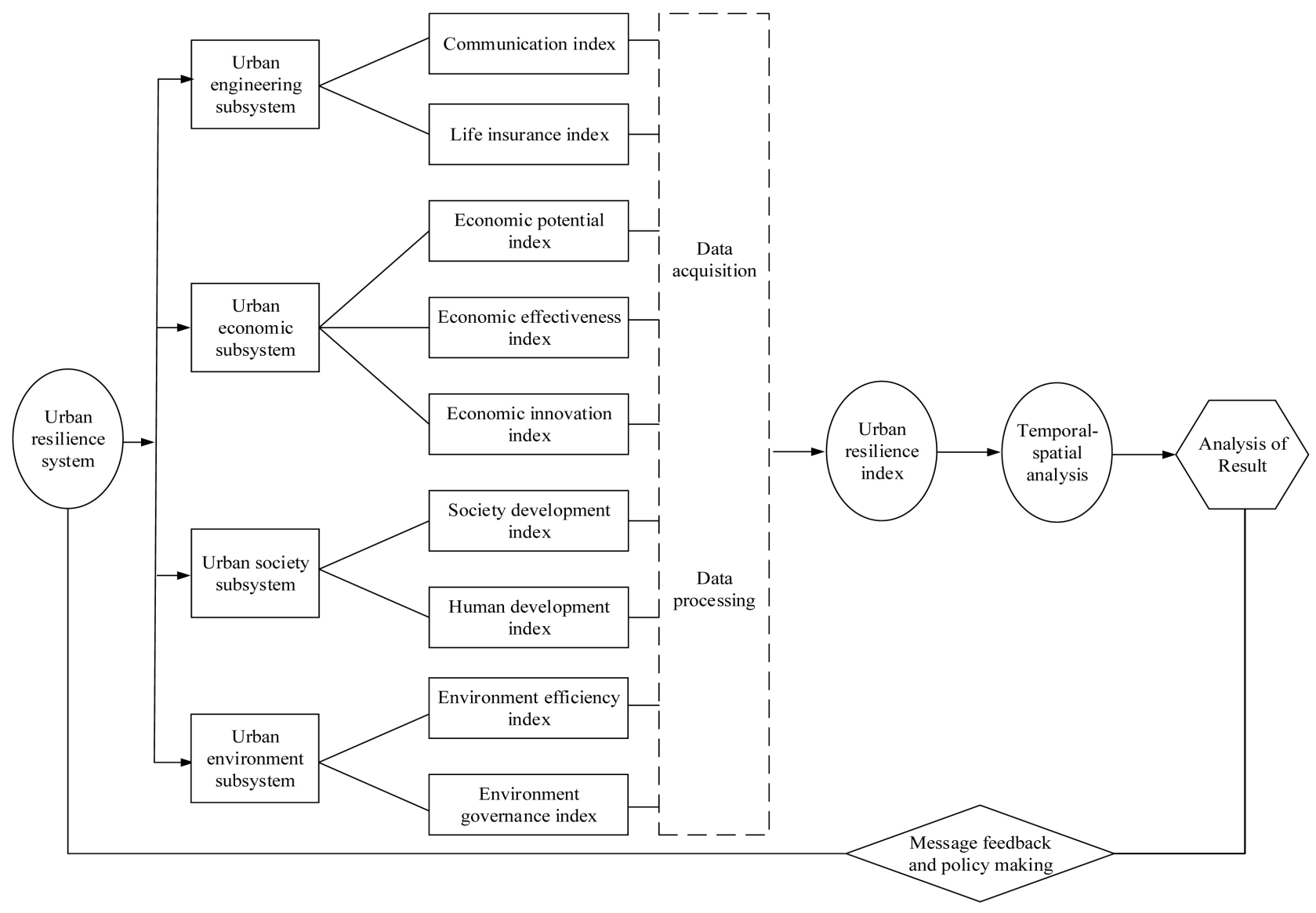

Figure 1. Research technique route. 
Table 1. The evaluation index of urban resilience.

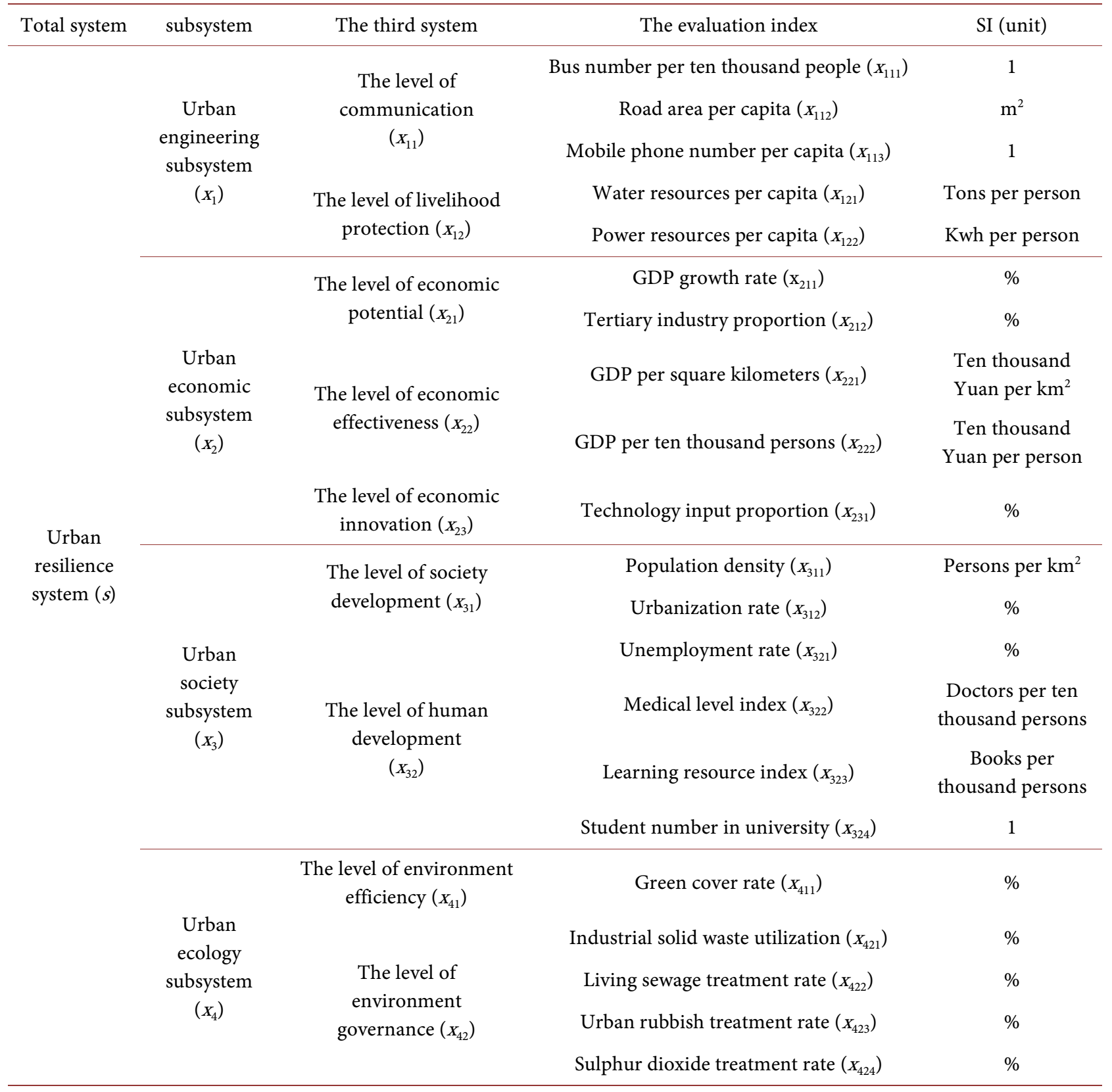

\subsection{Data Standardized}

The urban system is an organic whole of urban engineering subsystem, urban economic subsystem, urban society subsystem, and urban ecology subsystem. In urban synthetic system, those subsystems interacted each other. Therefore, the composite urban resilience system is expressed as: $S=f\left(x_{1}, x_{2}, x_{3}, x_{4}\right)$, where $x_{1}$ represents urban engineering subsystem, $x_{2}$ is on behalf of urban economic subsystem, $x_{3}$ is urban society subsystem, $x_{4}$ represents urban ecology subsystem, and $f$ is a composite function.

The indicator of the four subsystems is $x_{i j}=\left(x_{i j 1}, x_{i j 2}, \cdots, x_{i j k}\right), i \in[1, l]$, 
$j \in[1, m], l \geq 1, m \geq 1$. It can describe running state of four subsystems (ij) about urban engineering subsystem, urban economic subsystem, urban society subsystem, and urban ecology subsystem. Where $\alpha_{i j k}$ is upper limit and $\beta_{i j k}$ is lower limit. There are $\beta_{i j k} \leq x_{i j k} \leq \alpha_{i j k}, k \in[1, n]$, and $n \geq 1$.

In addition, one indicator has two kinds: one is positive index. It is better when one index value is higher; conversely, it is the lower. The other is a negative index. It is better when one index value is lower. Data standardized about index $\left(x_{i j k}\right)$ can be defined.

$$
Y_{i j}\left(x_{i j}\right)=\left\{\begin{array}{l}
\frac{x_{i j k}-\beta_{i j k}}{\alpha_{i j k}-\beta_{i j k}}(i \in[1,4], j \in[1,3], k \in[1,4]), \text { when } x_{i j k} \text { is positive } \\
\frac{\alpha_{i j k}-x_{i j k}}{\alpha_{i j k}-\beta_{i j k}}(i \in[1,4], j \in[1,3], k \in[1,4]), \text { when } x_{i j k} \text { is negative }
\end{array}\right.
$$

where $y_{i j}\left(x_{i j}\right) \in[0,1]$. Its value is greater, and the contribution is higher.

\subsection{Index Weight}

At present, index weight methods include subjective method, objective method, and mixed method. The former has expert scoring method and Delphi method; the middle include entropy value method, standard deviation method and CRITIC method (Suárez et al., 2016); the latter is a mixture method subjective method and objective method. This study selected CRITIC method to do with weight of the index.

Firstly, confirming the effect of indexes:

$$
C_{k}=\delta_{k} \sum_{k=1}^{n}\left(1-r_{j k}\right), k \in[1,4]
$$

Among them, $C_{k}$ represents the impact of index $(k)$ in the subsystem, $\delta_{k}$ is half on the standard deviation of index $(k), r_{j k}$ represents the correlation coefficient between index $(j)$ and index $(k)$. The value of $C_{k}$ is greater, and it is more important to the subsystem.

Secondly, confirming the weight of index:

$$
\omega_{k}=\frac{C_{k}}{\sum_{k=1}^{n} C_{k}}, k \in[1,4]
$$

where $\omega_{k}$ is objective weight of index $(k)$. Then, the matrix of weight coefficient $R_{\omega}=\left\{\omega_{1}, \omega_{2}, \cdots, \omega_{k}\right\}$ will be gained.

\subsection{Index Model}

Firstly, the contribution of index $\left(y_{i}\right)$ can be shown by $y_{i j}\left(x_{i j}\right)$. For using of different forms of data, it is necessary to use the linear weighted sum method for data processing. The model of subsystem is followed.

$$
Y_{i}\left(x_{i}\right)=\sum_{q=1}^{p} \omega_{k} Y_{i j}\left(x_{i j}\right), w \geq 0, \sum_{q=1}^{p} \omega_{k}=1
$$

Secondly, urban resilience index for each city can be got from following fo- 
rum.

$$
S=\frac{1}{4} \sum_{q=1}^{4} Y_{i}\left(x_{i}\right), i \in[1,4]
$$

\section{Empirical Study and Results}

\subsection{Sampling and Data}

Sichuan province locate in Western China, which includes 21 cities, such as Chengdu city, Panzhihua City, Deyang City, Neijiang City, Mianyang City, Zigong City, Yibin City, Yi Autonomous Prefecture of Liangshan, Tibetan Autonomous Prefecture of Aba, and so on. Urban natural ecosystems are fragile, in recent years, natural disasters brought a serious threat to the urban security and urban development.

Relative data were collected about Sichuan province, including 21 cities. Index data came from Sichuan province statistical yearbook (2004-2014) and Chinese city statistics yearbook (2004-2014).

\subsection{Data Processing}

Firstly, according to Formula (1), standardized original data of the index by statistical software (SPSS21). Secondly, confirmed index weight for each city according to the former Formula (2) and Formula (3). Moreover, get urban subsystem resilience using Formula (4). Finally, using the Formula (5), urban resilience index was calculated respectively. Specific data are shown in Table 2.

\subsection{Data Analysis}

Table 3 shows urban resilience index of Sichuan province presented a rising trend from 0.188 in 2003 to 0.752 in 2013 . The change of urban resilience consists of two stages. On the first phase from 2003 to 2008, urban resilience of Sichuan province was promoted from 0.188 to 0.448 gradually. On the second phase from 2008 to 2013, it was promoted from 0.448 to 0.752 . Figure 2 shows that there was a inflect point in 2008. Because the Wenchuan earthquake happened at Tibetan Autonomous Prefecture of Aba in Sichuan province. Sichuan was mistaken as "unsafe" area. With the policy and resource support of nation, urban resilience index demonstrated an increasing tendency in 2009.

Specially, there were different from change of urban subsystem resilience. Urban engineering resilience presented a little change from 2003 to 2007, but it kept a rapid growth since 2008. Urban economic resilience had a growth trend from 2003 to 2013, but there was a drop point in 2008. Urban social resilience and urban ecology resilience kept increasing since 2003. Figure 3 shows that both urban engineering resilience and urban economic resilience were hit hard by the earthquake. After disaster, due to the attention of social public, urban four subsystem resilience had been rapidly promoted. Meanwhile, because of people's concern about ecological environment and social progress, urban ecology resilience and urban social resilience were getting better. 
B. Pu et al.

Table 2. Urban resilience index of 21 cities of Sichuan Province from 2003 to 2013.

\begin{tabular}{|c|c|c|c|c|c|c|c|c|c|c|c|}
\hline City/Year & 2003 & 2004 & 2005 & 2006 & 2007 & 2008 & 2009 & 2010 & 2011 & 2012 & 2013 \\
\hline Chengdu & 0.175 & 0.330 & 0.391 & 0.366 & 0.538 & 0.576 & 0.607 & 0.756 & 0.786 & 0.825 & 0.767 \\
\hline Zigong & 0.317 & 0.484 & 0.347 & 0.357 & 0.394 & 0.394 & 0.406 & 0.463 & 0.640 & 0.601 & 0.692 \\
\hline Panzhihua & 0.366 & 0.327 & 0.393 & 0.292 & 0.412 & 0.431 & 0.471 & 0.487 & 0.590 & 0.640 & 0.758 \\
\hline Luzhou & 0.292 & 0.485 & 0.447 & 0.520 & 0.360 & 0.380 & 0.421 & 0.491 & 0.676 & 0.677 & 0.781 \\
\hline Deyang & 0.307 & 0.451 & 0.401 & 0.357 & 0.432 & 0.386 & 0.422 & 0.503 & 0.661 & 0.702 & 0.694 \\
\hline Mianyang & 0.277 & 0.306 & 0.356 & 0.335 & 0.503 & 0.421 & 0.490 & 0.538 & 0.644 & 0.695 & 0.688 \\
\hline Guangyuan & 0.182 & 0.293 & 0.369 & 0.334 & 0.421 & 0.359 & 0.491 & 0.500 & 0.558 & 0.598 & 0.739 \\
\hline Suining & 0.264 & 0.434 & 0.300 & 0.480 & 0.468 & 0.510 & 0.589 & 0.521 & 0.584 & 0.571 & 0.645 \\
\hline Neijiang & 0.189 & 0.337 & 0.277 & 0.369 & 0.407 & 0.416 & 0.449 & 0.529 & 0.640 & 0.632 & 0.683 \\
\hline Leshan & 0.266 & 0.293 & 0.287 & 0.369 & 0.419 & 0.452 & 0.495 & 0.524 & 0.595 & 0.670 & 0.747 \\
\hline Nanchong & 0.257 & 0.293 & 0.298 & 0.374 & 0.500 & 0.446 & 0.455 & 0.444 & 0.502 & 0.603 & 0.633 \\
\hline Meishan & 0.229 & 0.354 & 0.344 & 0.498 & 0.464 & 0.450 & 0.401 & 0.404 & 0.466 & 0.531 & 0.668 \\
\hline Yibin & 0.345 & 0.388 & 0.358 & 0.411 & 0.546 & 0.574 & 0.462 & 0.529 & 0.609 & 0.674 & 0.670 \\
\hline Guang'an & 0.187 & 0.375 & 0.283 & 0.419 & 0.404 & 0.468 & 0.481 & 0.590 & 0.542 & 0.652 & 0.694 \\
\hline Dazhou & 0.294 & 0.366 & 0.436 & 0.485 & 0.604 & 0.576 & 0.457 & 0.474 & 0.551 & 0.595 & 0.534 \\
\hline Ya'an & 0.313 & 0.338 & 0.399 & 0.399 & 0.464 & 0.416 & 0.455 & 0.472 & 0.584 & 0.720 & 0.603 \\
\hline Bazhong & 0.267 & 0.377 & 0.319 & 0.379 & 0.366 & 0.415 & 0.439 & 0.472 & 0.551 & 0.559 & 0.681 \\
\hline Ziyang & 0.212 & 0.311 & 0.286 & 0.399 & 0.358 & 0.406 & 0.453 & 0.505 & 0.546 & 0.583 & 0.688 \\
\hline Aba & 0.104 & 0.206 & 0.233 & 0.285 & 0.275 & 0.342 & 0.441 & 0.486 & 0.627 & 0.697 & 0.850 \\
\hline Garzê & 0.105 & 0.241 & 0.215 & 0.312 & 0.312 & 0.426 & 0.498 & 0.588 & 0.735 & 0.672 & 0.930 \\
\hline Liangshan & 0.206 & 0.331 & 0.211 & 0.307 & 0.285 & 0.375 & 0.475 & 0.575 & 0.701 & 0.754 & 0.793 \\
\hline
\end{tabular}

Table 3. Urban subsystem resilience of Sichuan Province.

\begin{tabular}{cccccc}
\hline Year & Y1 & Y2 & Y3 & Y4 & 0.188 \\
2003 & 0.289 & 0.228 & 0.192 & 0.046 & 0.251 \\
2004 & 0.310 & 0.304 & 0.481 & 0.335 & 0.337 \\
2005 & 0.326 & 0.354 & 0.502 & 0.439 & 0.379 \\
2006 & 0.205 & 0.447 & 0.522 & 0.515 & 0.403 \\
2007 & 0.233 & 0.651 & 0.544 & 0.590 & 0.486 \\
2008 & 0.206 & 0.356 & 0.639 & 0.613 & 0.448 \\
2009 & 0.372 & 0.622 & 0.615 & 0.771 & 0.556 \\
2010 & 0.668 & 0.656 & 0.686 & 0.768 & 0.695 \\
2011 & 0.625 & 0.682 & 0.802 & 0.850 & 0.719 \\
2012 & 0.807 & 0.546 & 0.862 & 0.901 & 0.766 \\
\hline
\end{tabular}




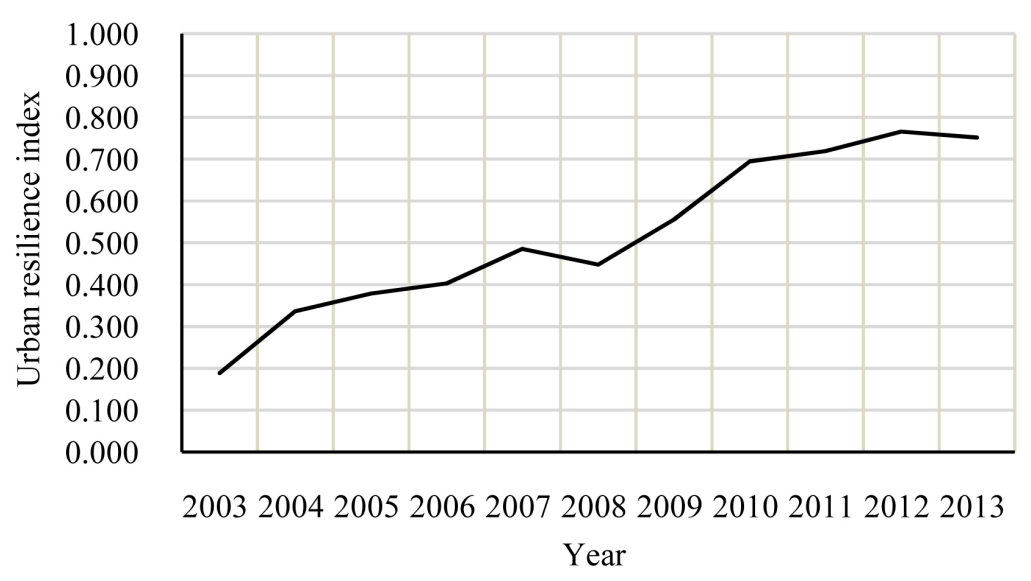

Figure 2. Urban resilience index of Sichuan Province.

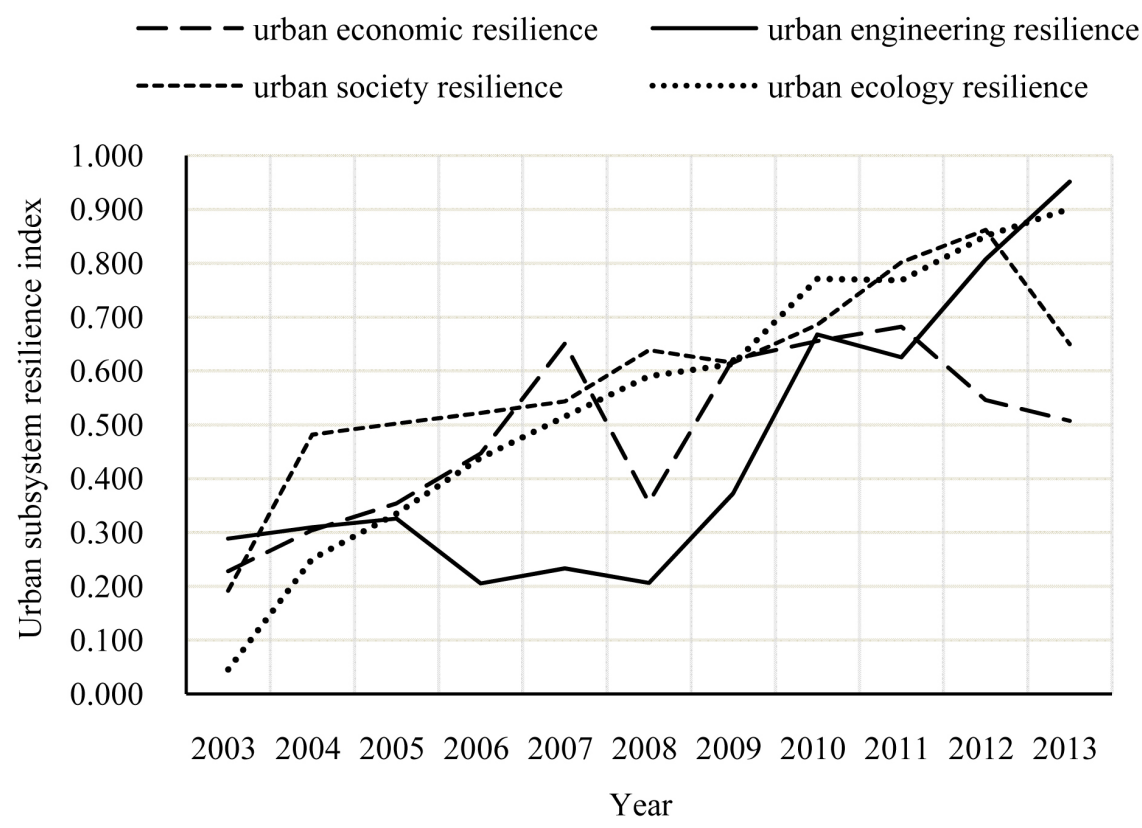

Figure 3. Urban subsystem resilience index of Sichuan Province.

LISA figure has been used for judging the temporal-spatial aggregation and differentiation of urban resilience of Sichuan province. Figure 4 shows that the urban resilience of Sichuan province had obvious spatial differentiation pattern in 2003 and 2008. High-low regional polarized city, Ya'an city, had appeared in 2003. This means that urban resilience of Ya'an city was relatively flexible, and its surrounding cities were low. High-high regional diffused city, Guang'an city, had appeared in 2008. This mean that urban resilience of Guang'an city was relatively flexible, and its surrounding cities were high too. In 2013, there were two regional diffused cities (Tibetan Autonomous Prefecture of Garzê and Tibetan Autonomous Prefecture of Aba), one low-high regional subsiding city (Ya'an city) and two low-low regional infectious cities (Guang'an city and Nanchong city), as showed in Table 4. 

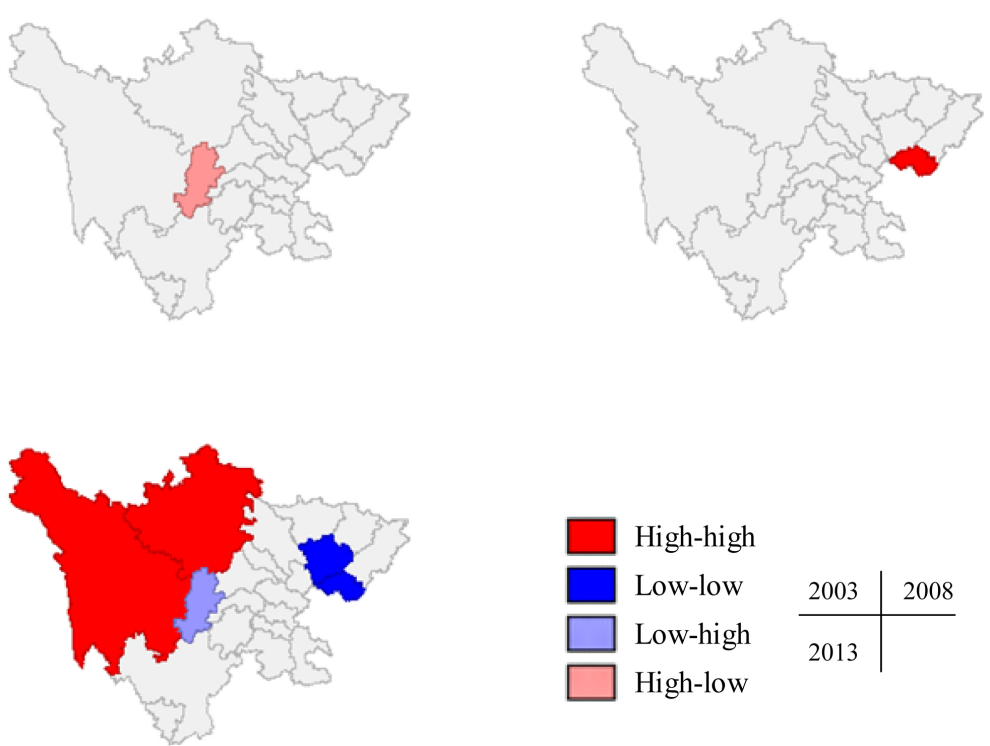

Figure 4. LISA figure of urban resilience index of Sichuan Province.

Table 4. Spatial differentiation type of Sichuan in 2013.

\begin{tabular}{cccc}
\hline Type & HH & LH & LL \\
\hline City Name & Aba, Garzê & Ya'an & Guang'an, Nanchong \\
City Number & 2 & 1 & 2 \\
\hline
\end{tabular}

\section{Conclusion and Implications}

Based on theories of resilient city and sustainable development, the model of urban resilience about urban engineering resilience, urban economic resilience, urban social resilience and urban ecology resilience was established, the advance state of them was evaluated. These are a basement of urban and regional integration progress with urban four subsystems.

\section{Limitations and Prospects}

This study has its limitations, for example, the data are only from yearbook. Meanwhile, this work is not covered with the social governance. Moreover, the index in our study has yet to be further improved. In the future, some studies towards urban resilience will be further. Firstly, urban resilience measure model will be improved by introducing weather indicators and local cultural indicators, such as air pollution, rate of blue sky, cultural exchange, cultural protection. Secondly, synergy development of urban subsystem will be strengthened, and change of urban subsystem resilience should be analyzed, and warning system about disaster should be formed. Thirdly, some case studies will be done for metropolis, such as Beijing, Shanghai, Chengdu, for their sustainable development. Finally, scope of relative research will be broadened, such as a regional research and a national research. 


\section{Acknowledgements}

The authors thank the "National Natural Science Foundation of China, grant number 71804119" and "China Postdoctoral Science Foundation, grant number 2019M663482".

\section{Conflicts of Interest}

The authors declare no conflict of interest.

\section{References}

Attoh-Okine, N. O., Cooper, A. T., \& Mensah, S. (2009). Formulation of Resilience Index of Urban Infrastructure Using Belief Functions. IEEE Systems Journal, 3, 147-153. https://doi.org/10.1109/JSYST.2009.2019148

Beilin, R., \& Wilkinson, C. (2015). Introduction: Governing for Urban Resilience. Urban Studies, 52, 1205-1217. https://doi.org/10.1177/0042098015574955

Campanella, T. J. (2006). Urban Resilience and the Recovery of New Orleans. Journal of the American Planning Association, 72, 141-146. https://doi.org/10.1080/01944360608976734

Childers, D. L., Pickett, S. T., Grove, J. M., Ogden, L., \& Whitmer, A. (2012). Advancing Urban Sustainability Theory and Action: Challenges and Opportunities. Landscape and urban Planning, 125, 320-328. https://doi.org/10.1016/j.landurbplan.2014.01.022

Cruz, S. S., Costa, J. P. T., de Sousa, S. Á., \& Pinho, P. (2013). Urban Resilience and Spatial Dynamics. In A. Eraydin, \& T. Taşan-Kok (Eds.), Resilience Thinking in Urban Planning (Vol. 106, pp. 53-69). Springer. https://doi.org/10.1007/978-94-007-5476-8_4

Cutter, S. L., Burton, C. G., \& Emrich, C. T. (2010). Disaster Resilience Indicators for Benchmarking Baseline Conditions. Journal of Homeland Security and Emergency Management, 7, 1-22. https://doi.org/10.2202/1547-7355.1732

Deppisch, S., \& Schaerffer, M. (2011). Given the Complexity of Large Cities, Can Urban Resilience Be Attained at All? In B. Müller (Ed.), German Annual of Spatial Research and Policy 2010 (pp. 25-33). Springer. https://doi.org/10.1007/978-3-642-12785-4_3

Desouza, K. C., \& Flanery, T. H. (2013). Designing, Planning, and Managing Resilient Cities: A Conceptual Framework. Cities, 35, 89-99.

https://doi.org/10.1016/j.cities.2013.06.003

Ernstson, H., van der Leeuw, S. E., Redman, C. L., Meffert, D. J., Davis, G., Alfsen, C. et al. (2010). Urban Transitions: On Urban Resilience and Human-Dominated Ecosystems. AMBIO, 39, 531-545. https://doi.org/10.1007/s13280-010-0081-9

Grimm, N. B., Faeth, S. H., Golubiewski, N. E., Redman, C. L., Wu, J., Bai, X. et al. (2008). Global Change and the Ecology of Cities. Science, 319, 756-760. https://doi.org/10.1126/science.1150195

Jha, A. K., Miner, T. W., \& Stanton-Geddes, Z. (2013). Building Urban Resilience: Principles, Tools, and Practice. World Bank. https://doi.org/10.1596/978-0-8213-8865-5

Leichenko, R. (2011). Climate Change and Urban Resilience. Current Opinion in Environmental Sustainability, 3, 164-168. https://doi.org/10.1016/j.cosust.2010.12.014

Lu, P. (2014). Spatial Planning and Urban Resilience in the Context of Flood Risk: A Comparative Study of Kaohsiung, Tainan and Rotterdam. Delft University of Technology.

Ouyang, M., \& Wang, Z. (2015). Resilience Assessment of Interdependent Infrastructure systems: With a Focus on Joint Restoration Modeling and Analysis. Reliability Engi- 
neering \& System Safety, 141, 74-82. https://doi.org/10.1016/j.ress.2015.03.011

Pu, B., \& Qiu, Y. (2015). A Bibliometric Analysis on Urbanization Research from 1984 to 2013. Open House International, 40, 37-43. https://doi.org/10.1108/OHI-03-2015-B0007

Pu, B., \& Qiu, Y. (2016). Emerging Trends and New Developments on Urban Resilience: A Bibliometric Perspective. Current Urban Studies, 4, 36-52. https://doi.org/10.1108/OHI-03-2015-B0007

Sellberg, M. M., Wilkinson, C., \& Peterson, G. D. (2015). Resilience Assessment: A Useful Approach to Navigate Urban Sustainability Challenges. Ecology and Society, 20, Article No. 43. https://doi.org/10.5751/ES-07258-200143

Suárez, M., Gómez-Baggethun, E., Benayas, J., \& Tilbury, D. (2016). Towards an Urban Resilience Index: A Case Study in 50 Spanish Cities. Sustainability, 8, Article No. 774. https://doi.org/10.3390/su8080774

Surjan, A., Sharma, A., \& Shaw, R. (2011). Understanding Urban Resilience. In R. Shaw, \& A. Sharma (Ed.), Climate and Disaster Resilience in Local Governments (pp. 17-45). Emerald Group Publishing Limited. https://doi.org/10.1108/S2040-7262(2011)0000006008

Tyler, S., \& Moench, M. (2012). A Framework for Urban Climate Resilience. Climate and Development, 4, 311-326. https://doi.org/10.1080/17565529.2012.745389

Vale, L. J. (2014). The Politics of Resilient Cities: Whose Resilience and Whose City? Building Research \& Information, 42, 191-201. https://doi.org/10.1080/09613218.2014.850602

Wilbanks, T., Fernandez, S., Backus, G., Garcia, P., Jonietz, K., Kirshen, P. et al. (2012). Climate Change and Infrastructure, Urban Systems, and Vulnerabilities. ISLAND Press.

Wilkinson, C. (2012). Social-Ecological Resilience: Insights and Issues for Planning Theory. Planning Theory, 11, 148-169. https://doi.org/10.1177/1473095211426274 